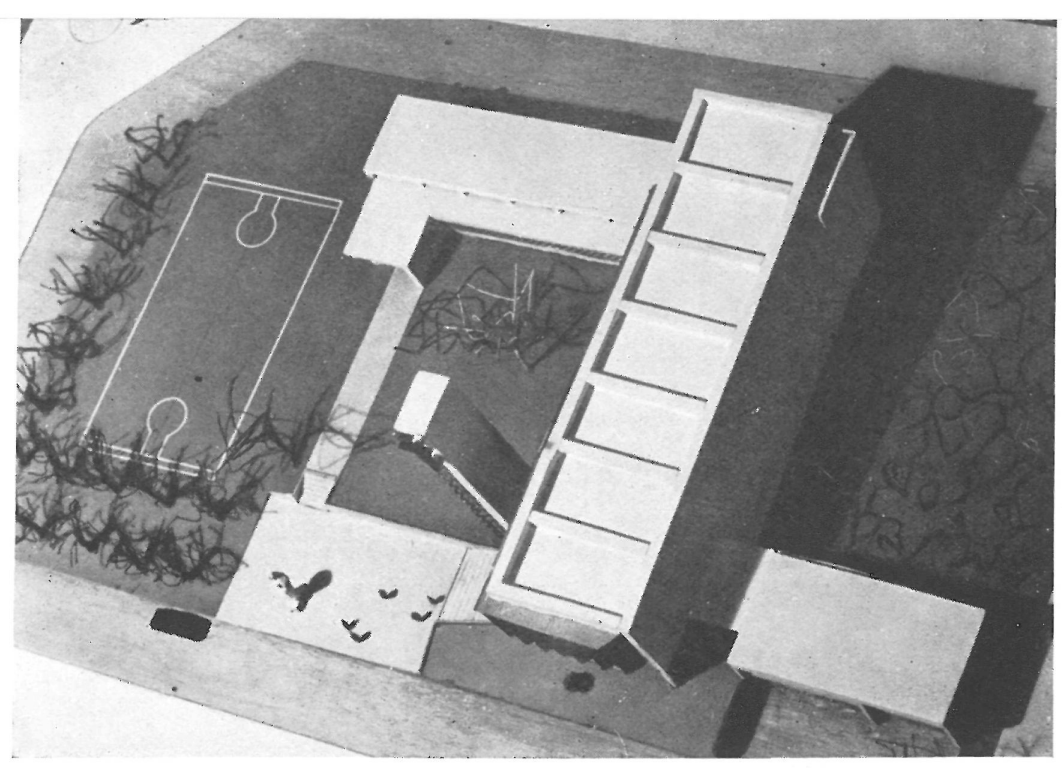

\title{
iglesia, en Belfort
}

MARCEL LODS, arquitecto

La iglesia de Santa Juana de Arco, en Belfort, responde a las necesidades de un centro parroquial, formando una unidad la iglesia, las clases y la casa del párroco, pero diferenciándose cada una de ellas por su distinta función y escala.

La nave de la iglesia domina en altura y nobleza al conjunto, adaptando una forma paralelepipédica, cuyas fachadas laterales son de gran diafanidad gracias al empleo de parteluces verticales de hormigón armado, que son al mismo tiempo los elementos estructurales sustentantes de la cubierta.

Junto a la nave, la esbelta torre pone un agudo acento vertical, de gran sencillez formal y belleza plástica. Su estructura, de hormigón armado, como en el resto de la obra, queda francamente acusada, formando atractivos paramentos de textura rugosa con la clara huella del encofrado.




a I zado

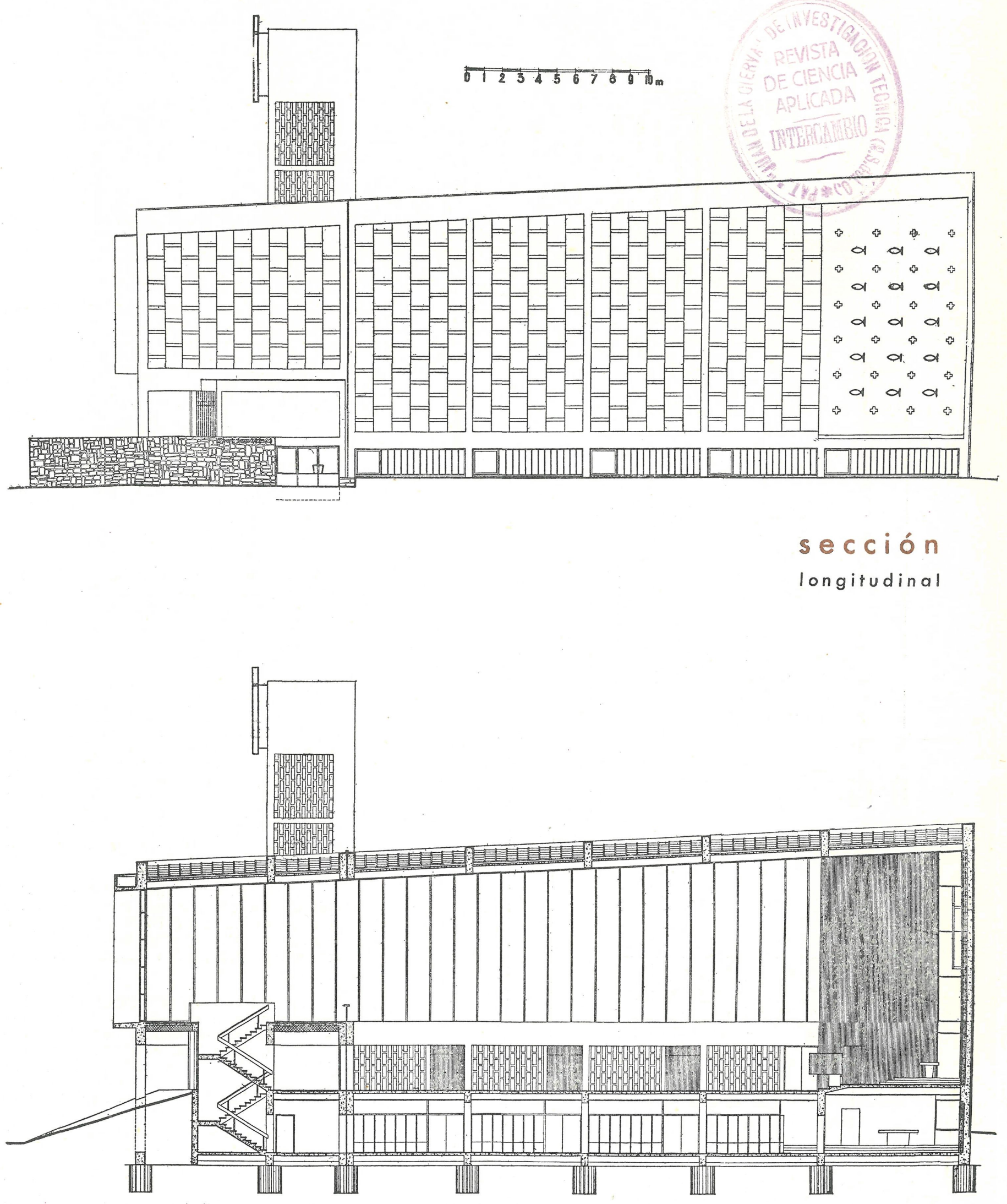





\section{zados frontales \\ sección transversal}

Una imagen de la Doncella de Orleáns recibe a los fieles en la pequeña lonja de entrada, desde la que se asciende a la iglesia por una amplia escalinata, mientras que otra más reducida lleva, por un sendero, a las clases.

A la entrada, y junto a la escalinata, se encuentra una bella vidriera de sencillo trazado, en el que aparece el pez bíblico como elemento central de la composición. Junto al altar mayor, la vidriera adopta sinuosos trazados arborescentes, resueltos con nervios de hormigón armado. Los parteluces de las migón armado. Los parteluces de las su paramento, están dispuestos de forma que la luz entra dirigida hacia el altar mayor.

La sinceridad constructiva de esta iglesia, así como la valentía de su autor en el tratamiento del hormigón armado, dan un alto valor arquitectónico a la ya meritoria concepción formal del conjunto.

Las zonas verdes proyectadas dan una impresión refrescante y tranquilizadora, mientras que el campo de deportes satisface las necesidades recreativas del centro docente, aislándolo, convenientemente, con una zona de vegetación alta, que lo separa de la vía de circulación y del jardín propio de la iglesia. No es extraño que el genio urbanístico de su autor se manifieste en la perfecta ordenación de volúmenes, estudio de circulaciones y ordenación de zonas verdes, buscando el aprovechamiento racional del suelo, del aire y del sol. 


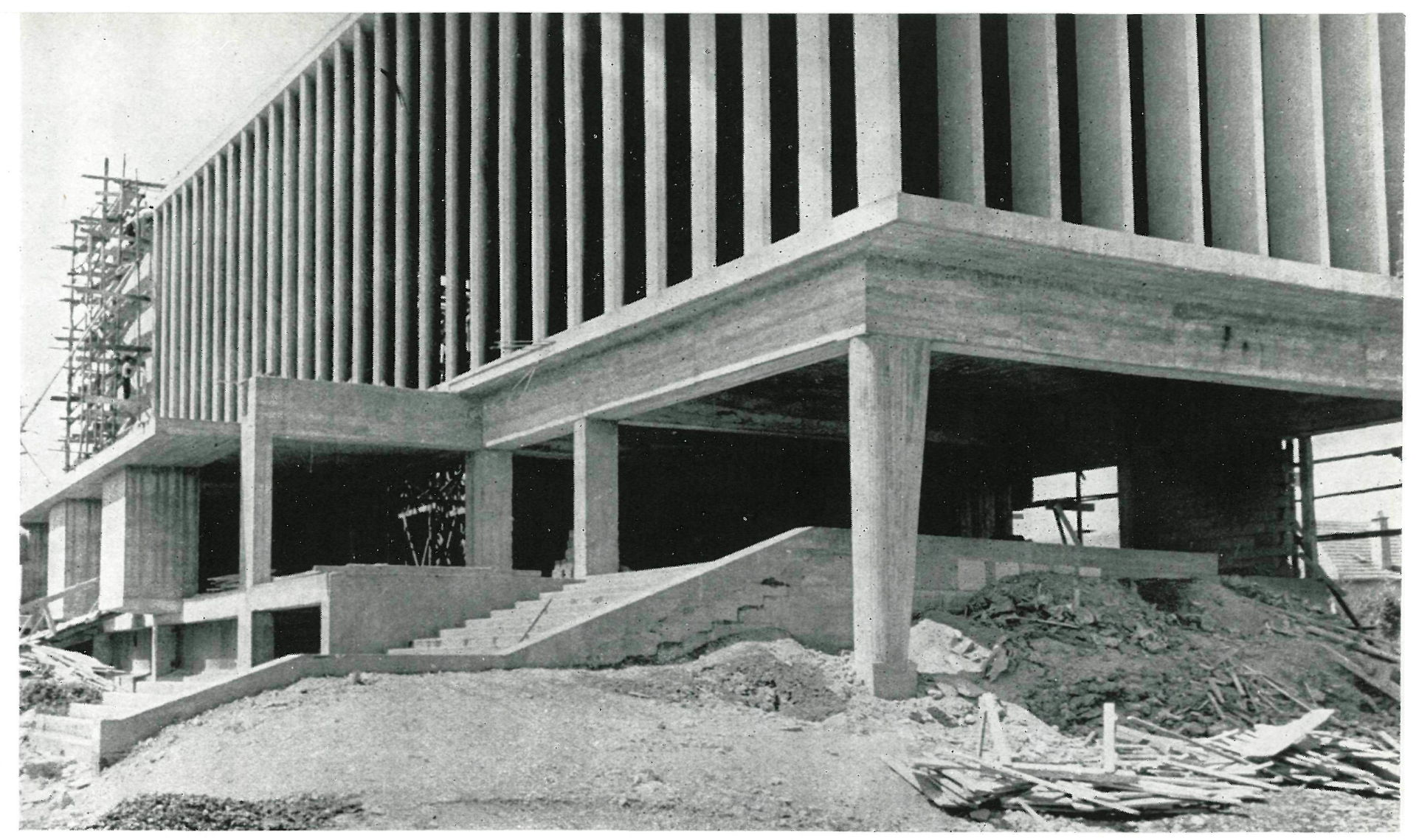

fases de obra

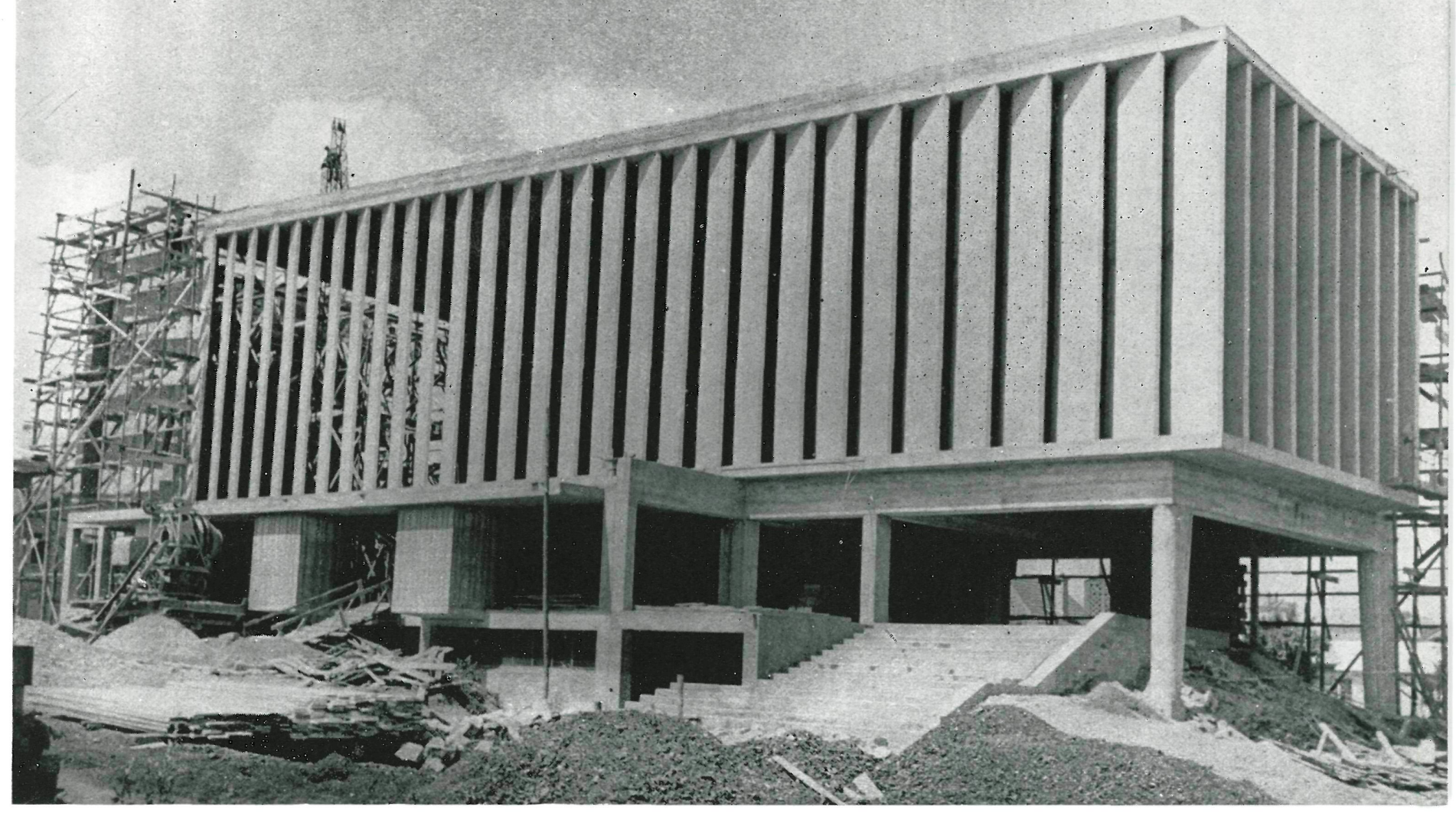


$p \mid a n t a$

campanario


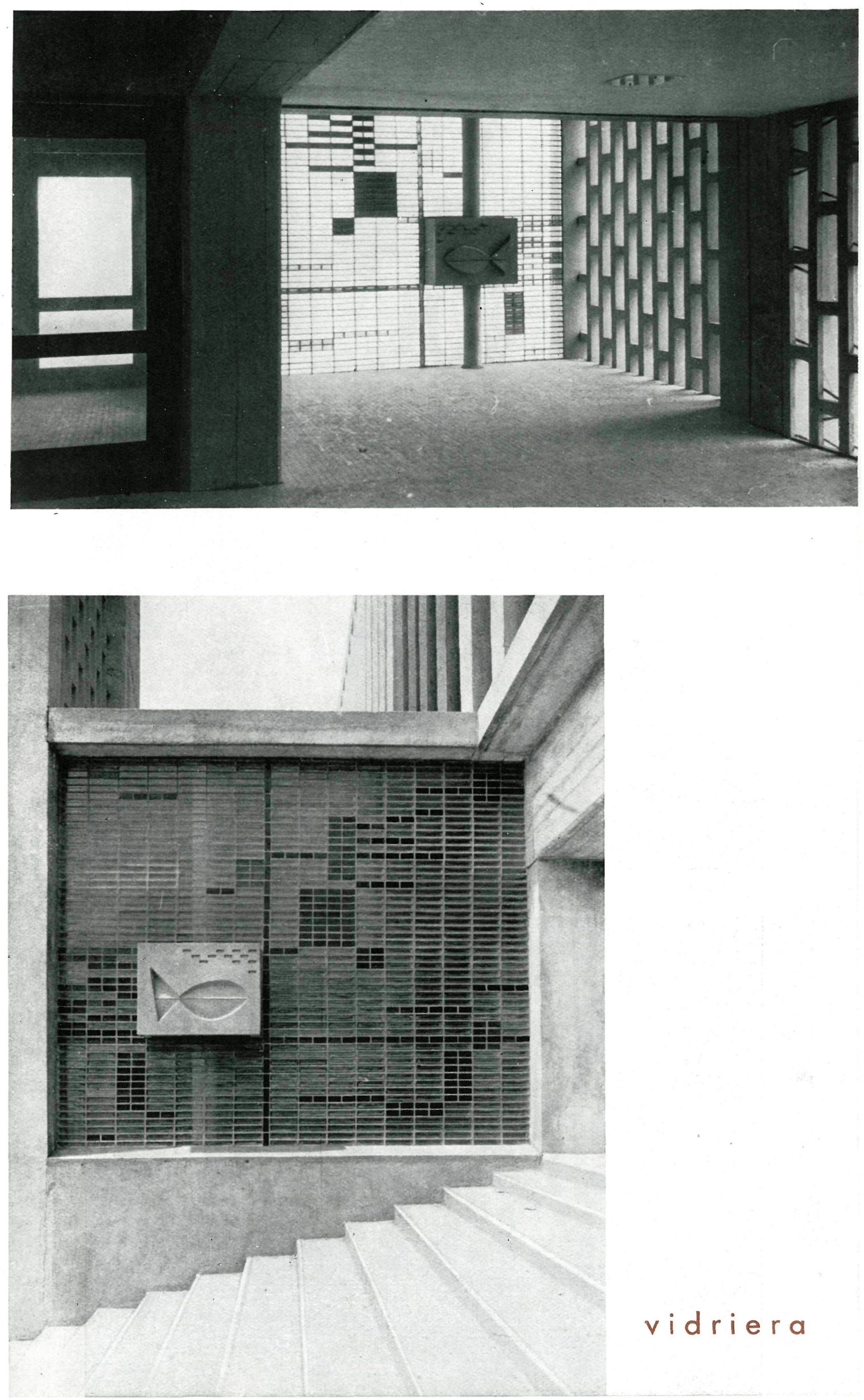

vidriera 


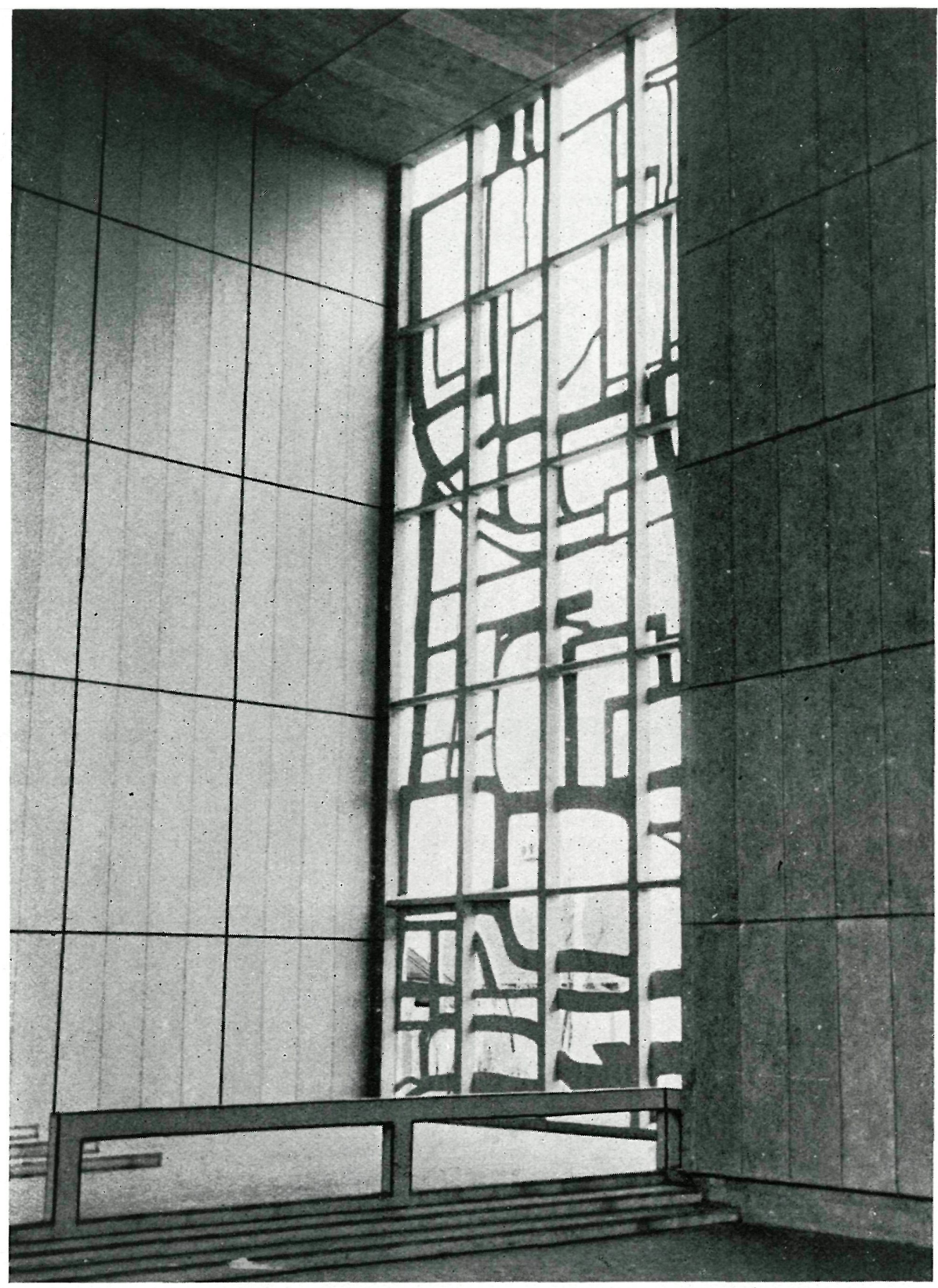

interiores

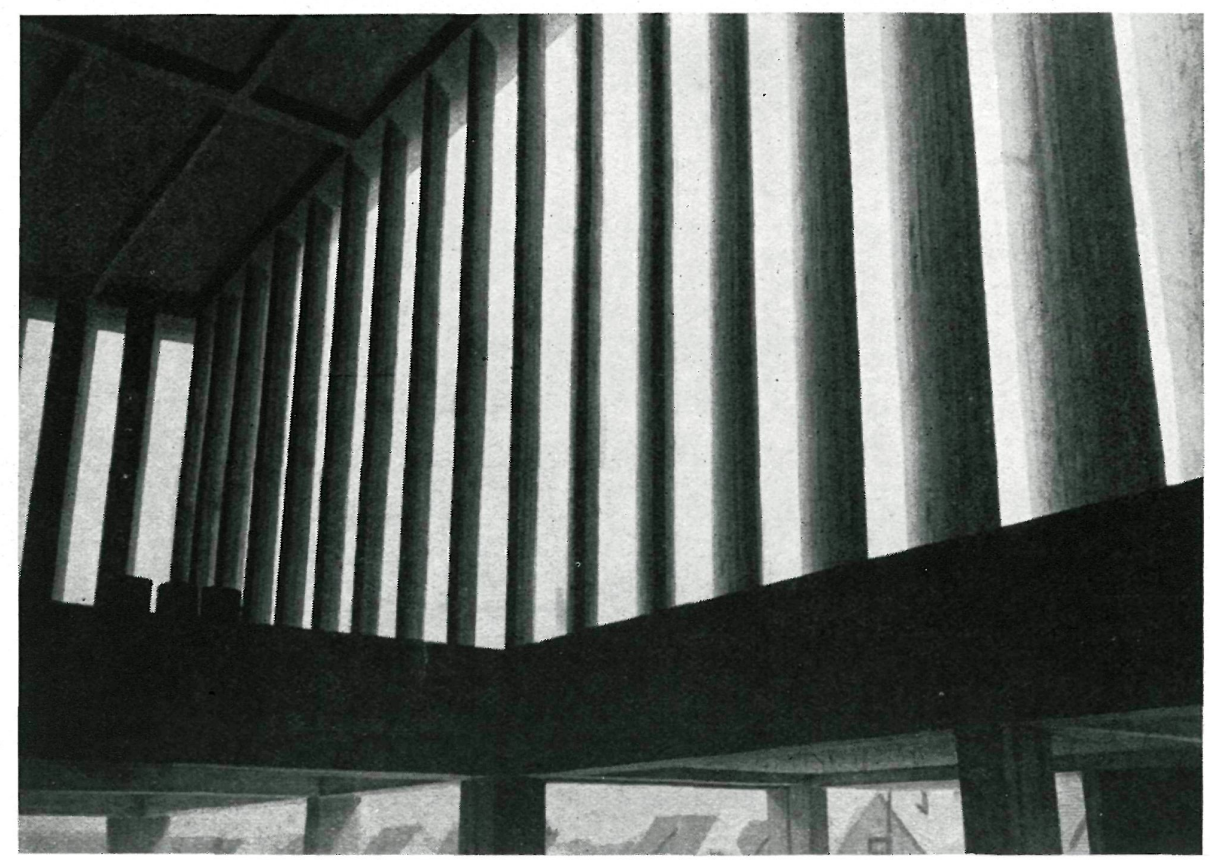

INFORMES DE LA CONSTRUCCION 8; 